\title{
Supertrees from Australia set to dominate the world?
}

Sydney

Australian "supertrees" are about to embark on a wave of world settlement. Having evolved to cope with the continent's arid environment, Australia's flora is among the toughest in the world, and the supertrees about to go overseas are the toughest of the tough. Trees are being developed with extraordinary capabilities such as salt tolerance, drought resistance, resistance to waterlogging, high rates of water transpiration and high growth rates.

A trial batch of salt-tolerant Red River Gums is already growing in Kuwait. Middle Eastern countries need extensive landscaping programmes around population centres, but there is hardly any rain and the little fresh water available is used for drinking. The only water available for plants is saline, so salt- and drought-tolerant trees are in demand.

The supertrees have been developed by collecting seeds from the healthiest trees growing in the harshest conditions throughout Australia, such as around salt lakes and along estuaries. Germinated and grown in glasshouses, the trees are subjected to increasingly severe conditions until only a few survive. Using tissueculture techniques, these survivors are then cloned for further trials and commercial mass propagation. Culturing and cloning ensures that each sample is genetically identical and so carries the desired characteristics of the parent plant. Selling the cloned saplings also eliminates the long wait for the trees to produce seeds.

Scientists from several universities and research laboratories are involved in the programme, including the mining company Alcoa, whose interest arises from its commitment to the reafforestation of mine sites. According to Dr Victor Harvey of the Commonwealth Scientific and Industrial Research Organisation's Division of Forest Research, tolerance to water with salt concentrations up to twice that of sea water have been achieved.

Scientists are also working on further improvements to the performance of the trees by inoculating them with specific plant-root fungi (ectomycorrizas) that live in a symbiotic relationship with the trees and can enhance their ability to resist environmental stresses such as salinity and improve their ability to take up nutrients from the soil, leading to faster growth.

This latest wave of Australian migrants will include various species such as the wattle (Acacia) and the Australian sheoak (Allocasuarina) as well as the common eucalypt. This programme should answer criticisms often levelled at the eucalypt by farmers in developing countries, that their foliage cannot be used as animal fodder. The fast-growing trees will be valuable in many of the developing countries as sources of firewood, for re-afforestation and for production of pulpwood.

Charles Morgan

\section{NASA welcomes whistle-blowers}

Washington

Armost eighteen months after the Challenger disaster, the National Aeronautics and Space Administration (NASA) is still trying to come to grips with the acknowledged failures of its safety review procedures. Officials announced last week that an independent body will be set up to screen expressions of anxiety, concerns and complaints before passing them on, anonymously, to NASA's own analysts.

Under the new system, which is modelled on a scheme developed by the Federal Aviation Administration (FAA), employees of NASA and its numerous contractors will be encouraged to communicate their worries to an independent facility at the Battelle Memorial Institute in Columbus, Ohio. Cranks and hoaxers will, it is hoped, be sifted out, and genuine concerns will go on to NASA for action.

The advantage of this system, according to NASA, is that it provides a regulated mechanism by which safety problems can be brought up in confidence and formally dealt with. Hitherto, anonymous comseriously, while the fear of retribution dissuaded many from attaching their names to letters. Problems stayed hidden, a state of affairs which was largely responsible for the Challenger explosion.

The new procedure will initially cover only space shuttle and orbiter operations, but should spread to all of NASA's departments. Although the shuttle accident led, eventually, to a recognition of organizational problems within NASA, it did not by itself produce solutions. Many employees reacted by "going into a cocoon", as one NASA spokesman put it. The changes now being put into effect are supposed to encourage a more open atmosphere within the agency so that problems may be handled openly and efficiently.

For the time being, at least, the Battelle Institute has no responsibility beyond notifying NASA of a problem. Anyone who wishes to ensure that a complaint has not become lost in the bureaucracy can check on progress only by abandoning anonymity. plaints have not always been treated

\section{Austro/Czech alarm over nuclear safety}

London

$A_{N}$ apparent error in translation has caused considerable anxiety about nuclear safety on both sides of the Austrian/ Czechoslovak frontier. Mention in the Slovak daily Pravda of "discrepancies" between the Soviet designs for nuclear power station and the actual construction of such stations in Czechoslovakia was rendered into German as "defects", "errors" or "breakdowns". The Pravda article described the visit of a group of Soviet experts to the Czechoslovak nuclear-power stations where further units are under construction, and said that in checking the construction against the blueprints, 135 discrepancies were noted at Jaslovske Bohunice, 221 at Dukovany and "several more" at the Mochovce construction site.

The Pravda article appeared on Friday, 8 May. By the following Monday the Austrian media had given wide publicity to the supposed "defects". Two days later, the Chief Inspector of the Czechoslovak nuclear safety authority Jiri Beranek convened a press conference at the Czechoslovak embassy in Vienna to explain what was meant by "discrepancies". Nuclear power stations in Czechoslovakia, he said, are built to Soviet designs but to Czechoslovak technical and safety standards, which in many cases are stricter than the Soviet ones. Standards for electrical installations, in particular switches, circuit-breakers and colourcoded cables, differ considerably. Other discrepancies refer merely to a slight difference in siting a door or window. Nevertheless, because a Soviet blueprint is used, it is necessary to draw up a special protocol for each deviation and to apply appropriate tests and acceptance procedures. These changes are naturally reported to the Soviet design team, although the latter act only as advisers and no Soviet experts act as inspectors at any stage of the construction or operation of Czechoslovak nuclear power stations.

Unfortunately, by this time, Austrian television had carried the story of the alleged "defects", and this had been seen in western Czechoslovakia, causing further alarm. Beranek had to repeat his explanations for the domestic audience, and the Czechoslovak Minister of Fuel and Power, Vlastimil Ehrenberger, made a similar statement in the federal assembly. Czechoslovak fears, however, have not been fully allayed, and Beranek has since found it necessary to give yet another press conference and radio interview on nuclear safety. 